\title{
What are the odds? The neural correlates of active choice during gambling
}

\author{
Bettina Studer ${ }^{1,2}$, Annemieke M. Apergis-Schoute ${ }^{1,2}$, Trevor W. Robbins ${ }^{1,2}$ and Luke Clark ${ }^{1,2}$ \\ 'Behavioural and Clinical Neuroscience Institute, University of Cambridge, Cambridge, UK \\ ${ }^{2}$ Department of Experimental Psychology, University of Cambridge, Cambridge, UK
}

\section{Edited by:}

Ming Hsu, University of California

Berkeley, USA

\section{Reviewed by:}

O'Dhaniel A. Mullette-Gillman, National University of Singapore, Singapore

Lusha Zhu, Virginia Tech Carilion

Research Institute, USA

Adam Craig, University of South

Florida, USA

*Correspondence:

Bettina Studer, Department of Psychology, University of Basel, Missionsstrasse 62A, 4055 Basel, Switzerland.

e-mail:bettina.studer@unibas.ch
Gambling is a widespread recreational activity and requires pitting the values of potential wins and losses against their probability of occurrence. Neuropsychological research showed that betting behavior on laboratory gambling tasks is highly sensitive to focal lesions to the ventromedial prefrontal cortex (vmPFC) and insula. In the current study, we assessed the neural basis of betting choices in healthy participants, using functional magnetic resonance imaging of the Roulette Betting Task. In half of the trials, participants actively chose their bets; in the other half, the computer dictated the bet size. Our results highlight the impact of volitional choice upon gambling-related brain activity: Neural activity in a distributed network - including key structures of the reward circuitry (midbrain, striatum) - was higher during active compared to computer-dictated bet selection. In line with neuropsychological data, the anterior insula and vmPFC were more activated during self-directed bet selection, and responses in these areas were differentially modulated by the odds of winning in the two choice conditions. In addition, responses in the vmPFC and ventral striatum were modulated by the bet size. Convergent with electrophysiological research in macaques, our results further implicate the inferior parietal cortex (IPC) in the processing of the likelihood of potential outcomes: Neural responses in the IPC bilaterally reflected the probability of winning during bet selection. Moreover, the IPC was particularly sensitive to the odds of winning in the active-choice condition, when the processing of this information was required to guide bet selection. Our results indicate an important role of the IPC in human decision-making under risk and help to integrate neuropsychological data of risk-taking following vmPFC and insula damage with models of choice derived from human neuroimaging and monkey electrophysiology.

Keywords: betting, choice, fMRI, inferior parietal cortex, ventromedial prefrontal cortex, reward

\section{INTRODUCTION}

Gambling is a common recreational activity in which a bet, typically a sum of money, is placed on an uncertain prospect. Gambling can be seen as a form of decision-making under risk and requires pitting the subjective values of potential wins and losses against their probability of occurrence. Abnormal betting on laboratory gambling tasks has been observed in a number of psychiatric disorders that are characterized by impairments in everyday decisionmaking, such as addictions (Lawrence et al., 2009), bipolar disorder (Murphy et al., 2001; Roiser et al., 2009), and schizophrenia (Hutton et al., 2002). Neuropsychological research using the Cambridge Gamble Task (CGT) has further shown that laboratory betting behavior is highly sensitive to focal brain injury. Patients with lesions to the ventromedial prefrontal cortex (vmPFC) show increased overall betting (Mavaddat et al., 2000; Manes et al., 2002; Clark et al., 2003, 2008), while a group of patients with insula damage were impaired in adjusting their bets to the chances of winning (Clark et al., 2008). These results indicate that the anterior insula and the vmPFC are critically involved in betting decisions. In healthy participants, previous neuroimaging studies revealed that the vmPFC and anterior insula, among other structures, are activated during valuation of risky response options (e.g., Chib et al., 2009) and during anticipation of uncertain outcomes (for reviews, see Ernst and Paulus, 2005; Krain et al., 2006; Knutson and Greer, 2008; Liu et al., 2011). While the results of these studies on valuation are compatible with the aforementioned neuropsychological work, the neural responses to bet selection as the most direct analog of gambling-related choice in healthy humans have rarely been studied. In the current study, we administered the Roulette Betting Task (Studer and Clark, 2011), in which participants are asked to place bets on risky gambles with varying chances of winning, to healthy volunteers and assessed the neural responses during bet selection by use of functional magnetic resonance imaging (fMRI).

Our first aim was to investigate differences in neural responses during active and passive selection of bets. Research on real-life gambling has highlighted a key influence of active choice upon risk-taking behavior. Even in games of pure chance, gamblers prefer situations that allow direct choice or manual control, and place higher bets under such conditions, a phenomenon termed the "illusion of control" (Langer, 1975; Ladouceur and Mayrand, 1987; Davis et al., 2000). We have recently shown that the requirement for 
active choice boosts selection-related psychophysiological arousal during laboratory gambling (Studer and Clark, 2011). Furthermore, prior fMRI studies revealed that neural responses to the presentation of wins and losses in the striatum are enhanced under conditions of instrumental choice (Coricelli et al., 2005; Rao et al., 2008; Camille et al., 2011). In contrast, the influence of the requirement for active choice upon neural activity at the time of selection remains largely unstudied. In the current study, we compared neural responses during active (i.e., volitional, selfdirected) versus computer-dictated selection of the bet amount. We hypothesized that neural activity during the selection phase in the brain reward circuitry, specifically in the striatum, would be higher in the active-choice condition.

Our second goal was to assess how the chances of winning are represented in the brain during the selection of bets. We reasoned that areas guiding risk-sensitive choice would be more responsive to the chances of winning during active compared to passive bet selection. Previous fMRI research assessing neural activity during outcome anticipation consistently found that neural responses in the anterior insula and vmPFC are modulated by the likelihood of potential outcomes (Critchley et al., 2001; Knutson et al., 2005; Preuschoff et al., 2006, 2008; Yacubian et al., 2006; Tobler et al., 2007; Rolls and Grabenhorst, 2008). The neural representation of the chances of winning during the selection phase, i.e., during the decision process per se, is less clear. A small number of previous fMRI studies indicate that, in addition to the anterior insula and vmPFC, the inferior parietal cortex (IPC) reflects the probability of potential outcomes during the choice window (Huettel et al., 2005; Van Leijenhorst et al., 2006; Smith et al., 2009). In close parallel, electrophysiological research in non-human primates reported that firing rates of neurons in the posterior parietal cortex co-vary with the reward likelihood during response selection (Shadlen et al., 1996; Platt and Glimcher, 1999; Shadlen and Newsome, 2001; McCoy and Platt, 2005; Kable and Glimcher, 2009). Thus, we hypothesized that neural activity in the IPC, anterior insula, and vmPFC would reflect the likelihood of winning during bet selection, particularly in the active-choice condition.

Our design also allowed the investigation of brain responses modulated by bet size. Previous fMRI studies found that the striatum and medial OFC are sensitive to the magnitude (and expected value) of potential rewards during outcome anticipation (Knutson et al., 2001, 2005; Yacubian et al., 2006; Tobler et al., 2007; Tom et al., 2007). Based on these results, we hypothesized that the striatum and the vmPFC would be sensitive to the bet size during the selection phase.

\section{MATERIALS AND METHODS PARTICIPANTS}

Right-handed male healthy volunteers $(n=41)$ took part in this study (mean age $=24$ years, $\mathrm{SD}=4$ ) and attended a single MRI session following a screening appointment. Volunteers were prescreened to exclude MRI contraindications, regular use of drugs, regular gambling, and prior history of neurological or psychiatric illness. The study was approved by the national research ethics committee and was conducted in accordance with the Declaration of Helsinki. All participants gave written informed consent, and were reimbursed $£ 40$ for participation plus a variable bonus depending on their final score in the task, which participants were

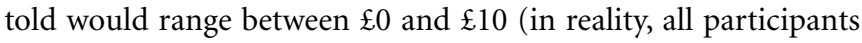

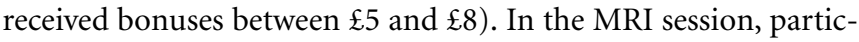
ipants received the task instructions and 10 practice trials before entering the scanner. Light head restraints were used to limit participant's head movement during MRI data acquisition. Two participants were excluded from analysis; one due to technical problems with the MRI scanner, the other due to problems with the normalization of MRI data.

\section{TASK}

Participants were administered the Roulette Betting Task (Studer and Clark, 2011), a computerized task that assesses risk-sensitive decision-making. The task was programmed in Visual Basic 2008 (Microsoft Corp., Redmond, WA, USA). Participants viewed the computer monitor through a mirror fitted on top of the head coil and used a MRI-compatible button box to make their choices. Participants completed three runs of the task; each run consisted of 25 trials and lasted about $10 \mathrm{~min}$. Each trial consisted of three phases: selection, anticipation, and feedback (see Figure 1). At the beginning of each trial, a fixation cross was displayed for a variable inter-trial interval, drawn from an exponential distribution ranging from 4 to $10 \mathrm{~s}$. Subsequently, a wheel with 10 red and blue segments was presented, along with three bets. Participants were instructed that if the wheel stopped on a blue segment, they would win, and if the wheel stopped on a red segment, they would lose. The ratio of blue (winning) and red (losing) segments varied across trials, reflecting the chances of winning $(60,70$, or $80 \%)$. The presentation of the wheel initiated the selection phase: participants were asked to choose one of the three presented bet boxes by pressing a corresponding key on the button box. Two trial types were contrasted: "active-choice" trials, in which the participants were required to select the size of bet (10,50, or 90 points), and "no-choice" trials, in which all three bets boxes contained identical amounts. Once a response had been made, the corresponding bet box stayed highlighted until the end of the selection period (fixed duration $=3.5 \mathrm{~s}$ ). The wheel then spun (anticipation period), with a variable duration drawn from an exponential distribution ranging from 4 to $8 \mathrm{~s}$. The wheel stopped on one of the 10 segments, initiating the feedback period. If the wheel stopped on a blue segment, the chosen amount of points was won, and the outcome message "YOU WON [XX] POINTS" was presented. If the wheel stopped on red, the selected amount of points was lost, and the message "YOU LOST [XX] POINTS" appeared. The accumulated point score was presented to participants at the end of each run.

\section{DATA ACOUISITION AND PREPROCESSING}

Gradient echo T2*-weighted echo-planar images (EPIs) were acquired on a Siemens Tim Trio 3 Tesla magnet using a 32 slice axial oblique sequence, with a repetition time of $2 \mathrm{~s}$ (TE $30 \mathrm{~ms}$, flip angle $78^{\circ}$, voxel size $3.0 \mathrm{~mm} \times 3.0 \mathrm{~mm} \times 3.0 \mathrm{~mm}$, matrix size $64 \times 64$, field of view $192 \mathrm{~mm} \times 192 \mathrm{~mm}$, bandwidth $2442 \mathrm{~Hz}$ ). In order to reduce signal dropout in the orbitofrontal cortex, the plane of acquisition was individually tailored for each participant by aligning it with the base of brain (approximately $0^{\circ}$ to $-10^{\circ}$ to the anterior commissure - posterior commissure line). 


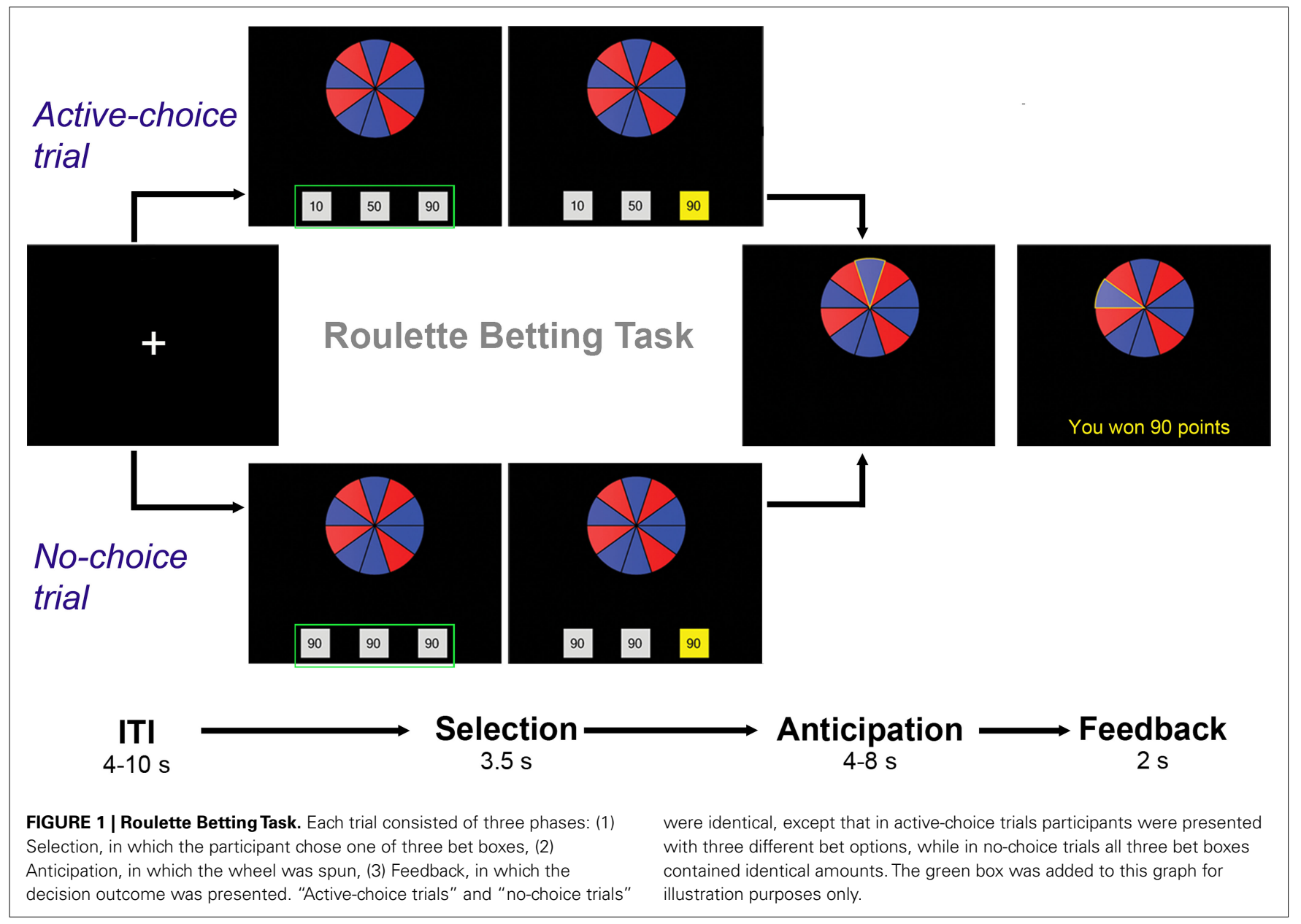

At the start of each of the three sessions, six dummy volumes were discarded to allow for equilibrium effects. Each run lasted a maximum of 360 repetitions ( $12 \mathrm{~min}$ ), but was terminated early on block completion. In addition, a high-resolution T1-weighted structural image was collected for each participant.

Processing and analysis of fMRI data was performed using SPM5 (Statistical Parametric Mapping, Wellcome Department of Cognitive Neurology, London, UK). Data preprocessing consisted of within-subject spatial realignment, spatial normalization, and spatial smoothing using an isometric Gaussian kernel with a full width at half-maximum of $10 \mathrm{~mm}$. Volumes were normalized to the International Consortium for Brain Mapping (ICBM) templates that approximate to Talairach and Tournoux (1988) space, using a matrix obtained from normalizing each subject's segmented structural scan onto the ICBM gray and white matter templates.

\section{DATA ANALYSIS}

For analysis of behavioral responses, the following two measurements were assessed for each trial: (a) response time, (b) selected bet amount (in active-choice trials only). Statistical analysis of behavioral data was conducted in SPSS (Version 15.0; SPSS Inc., Chicago, IL, USA). All statistical tests are reported two-tailed, and alpha was set at 0.05 .
We assessed event-related BOLD responses modeled to the selection and outcome phases of each trial, using a canonical hemodynamic response function implemented within a general linear model (GLM). Four event types were distinguished: activechoice trials and no-choice trials were modeled at selection onset using epoch functions with individual response times as the durations, and wins and losses were modeled at outcome with a duration length of $2 \mathrm{~s}$. The probability of winning and the bet size were added as parametric modulators onto the active-choice and no-choice selection regressors. Thus, a total of four parametric modulators were added to the GLM. The use of these decision variables as parametric modulators allows for the identification of brain areas in which the magnitude of BOLD responses correlates with the probability of winning and the bet size on a trial-by-trial basis. The design matrix hence comprised 8 columns [3 (selection: active choice $)+3$ (selection: no choice) +2 (feedback) $]$, plus the 6 movement parameters from spatial realignment as covariates of no interest.

Twelve subjects uniformly selected the highest bet option in all active-choice trials. The lack of any variation in the bet size in active-choice trials made the calculation of the parametric modulator impossible for these subjects; hence they were excluded from further analysis. The remaining 27 participants included in the final analysis selected a bet other than their 
most frequently chosen one in $7-58 \%$ of active-choice trials $($ Mean $=34 \%, \mathrm{SD}=13 \%)$.

Next, we calculated the following first-level single-subject contrasts for the selection phase:

(1) Active-choice versus no-choice trials.

(2) Parametric modulation by probability of winning during active-choice and no-choice trials.

(3) Parametric modulation by probability during active-choice minus parametric modulation by probability during no-choice trials.

(4) Parametric modulation by bet size during active-choice and during no-choice trials.

(5) Parametric modulation by bet size during active-choice minus parametric modulation by bet size during no-choice trials.

In the specified GLM, any shared variance between the two parametric modulators (probability of winning and bet size) is assigned to the probability modulator (entered first) through autoorthogonalization implemented in SPM. We chose this ordering of modulators in this primary GLM as it gives maximal explanatory power to the probability modulator (see Hare et al., 2008; Symmonds et al., 2010). As the chances of winning and the size of chosen bets were correlated in the active-choice trials in most subjects, we conducted a follow-up analysis in order to test whether the regions associated with the likelihood of winning were uniquely sensitive to the probability independent of bet size. Thus, a second GLM was calculated, in which the order of modulators was reversed (bet size entered first). The activations identified in the contrasts (2) and (3) in the primary GLM were then compared with the results obtained in the same contrasts in this second GLM.

The individual contrast images were taken to a second-level group analysis. One sample $t$-tests were calculated on the singlesubject contrast images. We first computed region-of-interest (ROI) analyses based on a priori hypotheses about the involvement of four brain regions in risky selection as discussed in the Introduction: (a) vmPFC (gyrus rectus, orbital parts of mid frontal gyrus, and orbital parts of superior frontal gyrus), (b) bilateral insula (c) bilateral striatum (caudate, putamen), (d) bilateral IPC (inferior parietal lobe, supramarginal gyrus, angular gyrus). PickAtlas (Maldjian et al., 2003, 2004) was used to create a single combined mask of the four ROIs defined anatomically using the Anatomical Automatic Labeling (AAL) Atlas (Tzourio-Mazoyer et al., 2002). Statistics within this ROI mask were thresholded at $P<0.05$ with false discovery rate (FDR) correction applied and an extent threshold of 10 voxels. AAL was used for voxel localization. Rfxplot software (Gläscher, 2009) was used to extract and display percent signal change or parameter estimates for peak voxels. To test for other foci outside the ROI mask that may be sensitive to the choice parameters, we also conducted exploratory whole-brain analyses at a less stringent level with statistical inferences performed at a level of $P<0.001$ uncorrected and a minimal cluster size of 10 voxels (see also Van Leijenhorst et al., 2006; Elliott et al., 2008; Sharot et al., 2009; Plassmann et al., 2010).

Two supplemental analyses were conducted to provide quality checking of our task against established effects and to facilitate comparison with previous work. First, although the goal of this study was to investigate neural correlates of decision-making (i.e., during selection), we compared outcome-related BOLD responses to wins and losses in a whole-brain analysis in order to validate our data in relation to the prior literature. The results of this analysis can be found in the Table A4 in Appendix. Second, a number of prior neuroimaging studies have assessed the neural representation of the expected value of choice options (e.g., Tobler et al., 2009; Symmonds et al., 2010). In order to allow the comparison of our data with this prior literature, we calculated an additional GLM: BOLD responses were modeled to the selection and outcome events as in the primary GLM, but with expected value [(probability of winning minus probability of losing) multiplied by bet amount] entered as a single parametric modulator to the selection regressors. We then identified areas that were sensitive to the expected value during active and passive bet selection, using the ROI and whole-brain approaches. The results of these analyses can be found in Tables A5 and A6 in Appendix.

Analysis of the behavioral data revealed considerable individual differences in betting behavior. Most importantly, participants varied considerably in the degree to which they adjusted their bets to the chances of winning in active-choice trials ("risk adjustment"). This tendency can numerically be expressed for each participant by calculating the change in average bet size in 60 and $70 \%$-trials compared to in 80\%-trials (Studer and Clark, 2011).We assessed whether this heterogeneity in choice behavior was related to individual differences in neural sensitivity during bet selection, and particularly neural responsiveness to the chances of winning, by entering risk adjustment as a co-variable in the following three group-level $t$-tests: (1) active-choice versus no-choice trials, (2) parametric modulation by the chances of winning in both choice conditions, (3) ratio $\times$ choice interaction. Whole-brain analysis $(P<0.001$ uncorrected, $k=10)$ was then conducted to identify areas where activity correlated with risk adjustment across participants.

\section{RESULTS \\ BEHAVIOR}

Analysis of behavioral data replicated our previous results on the same task administered outside the MRI scanner (see Studer and Clark, 2011 for details). Specifically, we first examined whether participants varied their bets in the active-choice condition. A oneway ANOVA showed a significant main effect of the likelihood of winning $\left[F(2,78)=47.31, P<0.001, \eta_{\mathrm{p}}^{2}=0.55\right]$, with bets rising with increasing likelihood (average chosen bet: trials with $60 \%$ probability of winning: $52 \pm 3$ points, $70 \%$-trials: $72 \pm 3$ points, 80\%-trials: $88 \pm 1$ points).

Response times were sensitive to the chances of winning and the requirement for active choice: a 3 (probability of winning) $\times 2$ (choice) repeated-measures ANOVA on the decision latencies revealed a significant probability $\times$ choice interaction $\left[F(2,78)=18.96, P<0.001, \eta_{\mathrm{p}}^{2}=0.33\right]$, as well as significant main effects of probability $[F(2,78)=50.82, P<0.001$, $\left.\eta_{\mathrm{p}}^{2}=0.57\right]$ and choice $\left[F(1,39)=5.21, P<0.05, \eta_{\mathrm{p}}^{2}=0.12\right]$. As expected, participants were faster to select their bet on nochoice trials compared to active-choice trials and deliberated less when the probability of winning increased, particularly in active-choice trials (active choice: 60\%-trials: $1691 \pm 67 \mathrm{~ms}$, $70 \%$-trials: $1517 \pm 64 \mathrm{~ms}, 80 \%$-trials: $1224 \pm 43 \mathrm{~ms}$, no choice: 
60\%-trials: $1433 \pm 73 \mathrm{~ms}, 70 \%$-trials: $1304 \pm 69 \mathrm{~ms}$, $80 \%$-trials: $1264 \pm 57 \mathrm{~ms})$.

\section{NEURAL CORRELATES OF ACTIVE CHOICE}

First, we compared neural activations during the selection phase in active-choice trials to brain responses during the selection phase in no-choice trials. The requirement for active choice was associated with higher responses in the caudate bilaterally (right: peak at $12,4,8 ; t=6.39$; left: peak at $-8,10,2 ; t=5.64)$, anterior insula bilaterally (right: peak at 32, 20, $4 ; t=5.25$; left: peak at $-34,26$, 2 ; $t=4.32$ ), IPC bilaterally (right: peak at $34,-48,40 ; t=4.57$; left: peak at $-24,-54,52 ; t=4.15$ ), and in the right OFC (peak at $3650-2 ; t=3.31$ ), compared to computer-dictated selection (see Figure 2). There were no foci within the ROI mask that displayed higher activity during passive selection.

An exploratory whole-brain analysis additionally showed an increased signal during active compared to passive selection in a number of areas outside the ROIs, including in the anterior cingulate cortex (BA32), midbrain, and superior parietal cortex (see Table A1 in Appendix). Within the IPC, both increased and decreased activations during active choice of bets compared to passive selection were observed in adjacent subregions. Note, however, that the ROI analysis only confirmed increased activation in the IPC during active choice of bets.

\section{NEURAL CORRELATES OF PROBABILITY OF WINNING}

Our second aim was to identify brain areas that are sensitive to the likelihood of winning during the selection phase. We reasoned that regions that subserve decision-making would predominantly be sensitive to the probability of winning in active-choice trials, when this information was used to guide choice.

The ROI analysis revealed such a probability $\times$ choice interaction in the mOFC (peak at $-6,26,-12 ; t=5.86$ ), angular gyrus bilaterally (right: peak at $60,-54,26 ; t=5.20$; left: peak at -56 , $-66,26 ; t=5.76$ ), supramarginal gyrus bilaterally (right: peak at $66,-22,22 ; t=4.08$, left: peak at $-50,-24,16 ; t=3.26)$, the anterior insula bilaterally (right: peak at $32,20,-20 ; t=4.23$; left: peak at $-28,16,-8 ; t=4.94$ ), and in the right caudate (peak at 10, 10, $-2 ; t=4.21$; see Figure 3). Whole-brain analysis (see Table A2 in Appendix) revealed additional responses (outside the ROI mask) in the medial superior frontal gyrus and the midcingulate cortex.

In a follow-up analysis, we tested whether these activations remained significant after the variance shared with the bet size modulator was removed from the estimation of the probability modulator. A second GLM with the order of parametric modulators reversed confirmed a significant probability $\times$ choice interaction in the mOFC (peak at $-4,26,-12 ; t=4.33$ ), angular gyrus bilaterally (right: peak at $62,-38,34 ; t=3.68$; left: peak at -50 , $-60,24 ; t=4.09$ ), right supramarginal gyrus (peak at $68,-44$,

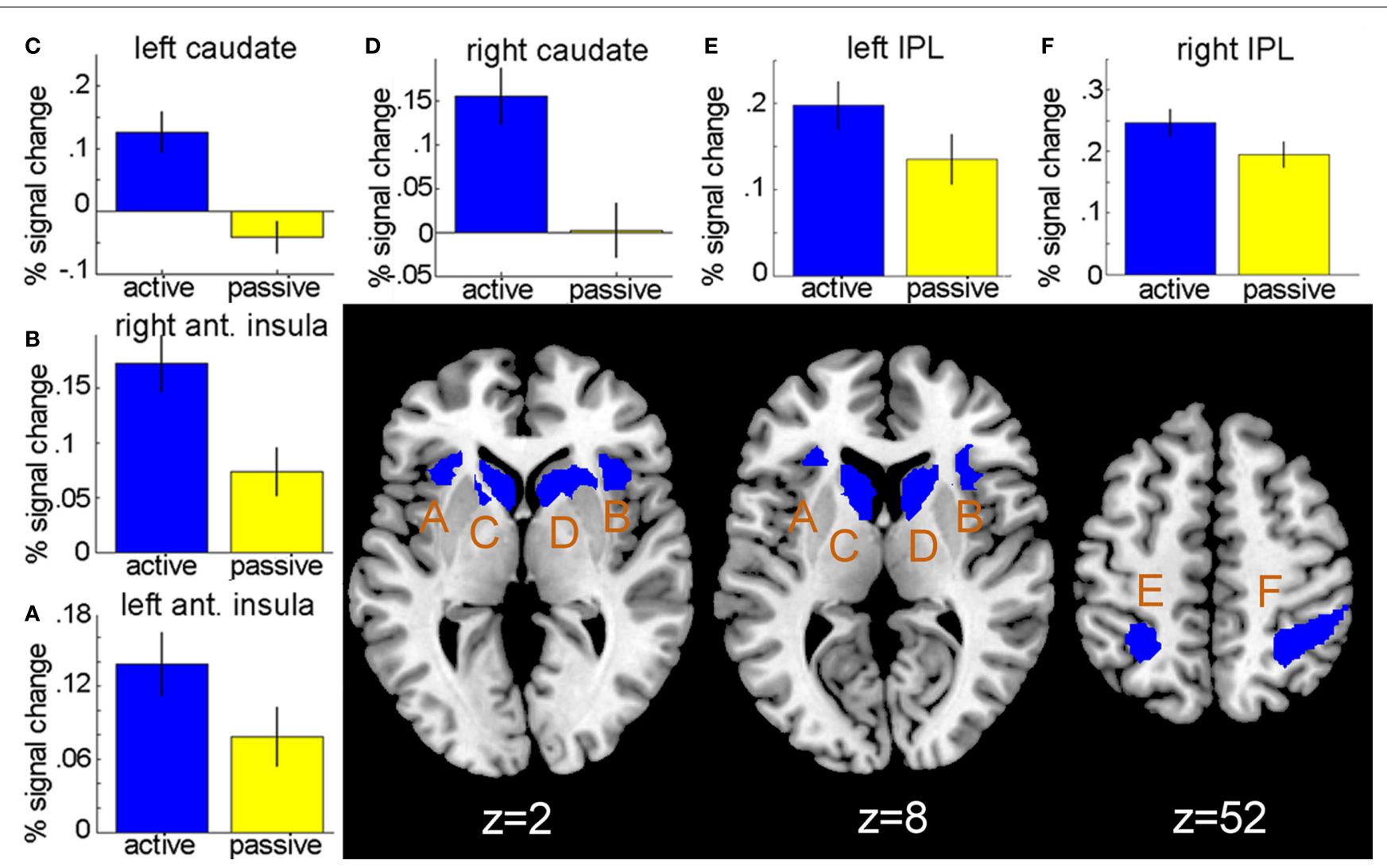

FIGURE 2 | Active versus passive selection of bets. $\mathrm{ROI}$ analysis revealed stronger activations during active choice of bets compared to

computer-dictated bet selection in the anterior insula bilaterally (peaks at -34 , $26,2 ; 32,20,4)$, the caudate bilaterally (peaks at $-8,10,2 ; 12,4,8$ ), and the inferior parietal lobe (IPL) bilaterally (peaks at $-24,-54,52 ; 34,-48,40$ ). Results are displayed at $P<0.05$, FDR-corrected. Bar graphs show percent signal change at peak voxels [(A,B): anterior insula, (C,D): caudate, $(\mathbf{E}, \mathbf{F})$ : IPL] during bet selection for the two choice conditions. Error bars represent SEM. 


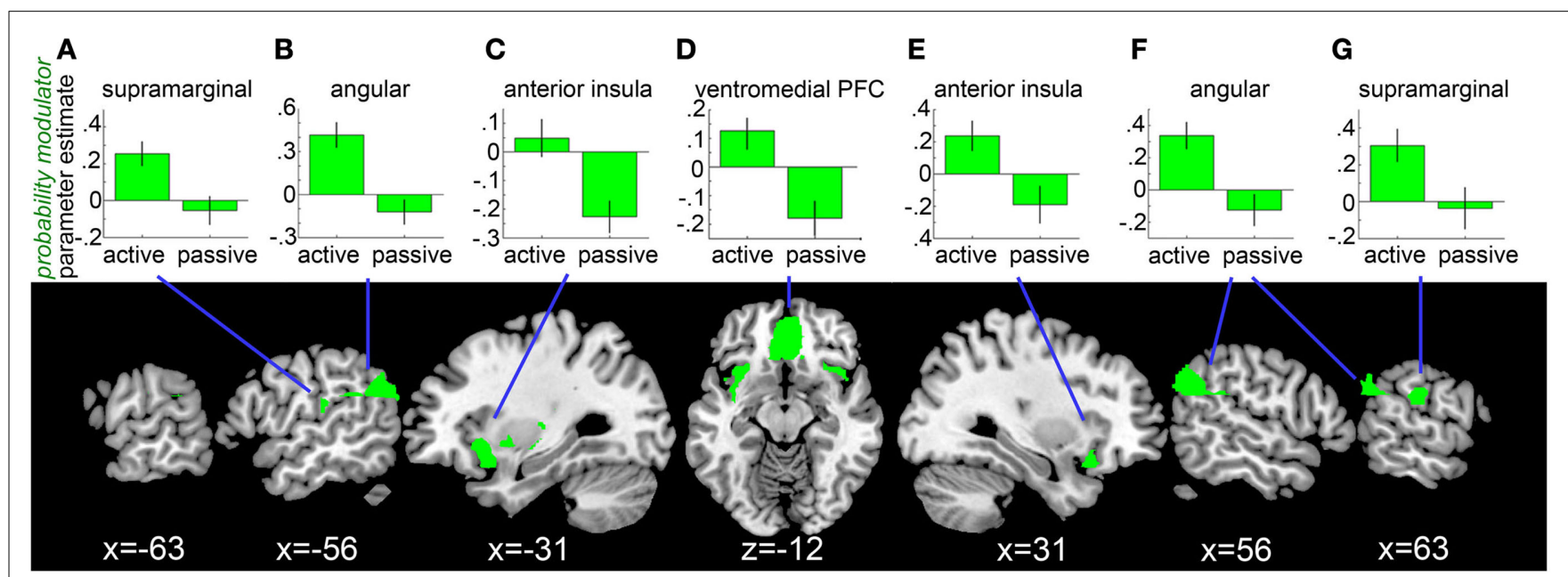

FIGURE 3 | Neural correlates of chances of winning during bet selection. $\mathrm{ROI}$ analysis revealed that neural responses in the supramarginal gyrus bilaterally (peaks at $-50,-24,16 ; 66,-22,22$ ), angular gyrus bilaterally (peaks at $-56,-66,26 ; 60,-54,26$ ), anterior insula bilaterally (peaks at $-28,16,-8 ; 32,20,-20$ ), and ventromedial prefrontal cortex (peak at $-6,26,-12$ ) are differentially modulated by the chances of winning during active versus passive bet selection. Results are displayed at $P<0.05$, FDR-corrected. Bar graphs show parameter estimates for the probability of winning modulator in the two choice conditions at peak voxels $[(\mathbf{A}, \mathbf{G})$ : supramarginal gyrus, $(\mathbf{B}, \mathbf{F})$ : angular gyrus, (C,E): anterior insula, (D): ventromedial prefrontal cortex]. Error bars represent SEM.
$24 ; t=3.16$ ), and the anterior insula bilaterally (right: peak at 30, $18,-20 t=3.52$; left: peak at $-38,-2,-14 ; t=4.82)$ in the ROI analysis. The results of the corresponding whole-brain analysis are described in Table A2 in the Appendix.

We also tested for brain areas that were modulated by the probability of winning independently of the choice condition. In the ROI analysis, no regions were significantly modulated by the probability of winning across both choice conditions. Whole-brain analysis found that neural responses in the left dlPFC, right posterior insula, and visual cortex, as well as in the left angular gyrus and left supramarginal gyrus, were correlated positively with the probability of winning in both active-choice and no-choice trials (see Table A2 in Appendix). A follow-up analysis (whole-brain) showed that BOLD responses in the left angular gyrus and visual cortex remained significantly modulated by the probability of winning in the second GLM, after removing variance shared with the bet size modulator (see Table A2 in Appendix). There were no areas identified in which activity was negatively correlated with the probability of winning (i.e., greater activity with lower likelihoods of winning) in either analysis.

\section{INDIVIDUAL DIFFERENCES IN GAMBLING-RELATED BRAIN ACTIVITY}

Exploratory analyses tested whether heterogeneity in behavioral performance was related to individual differences in neural activity during betting choices. Specifically, we examined whether behavioral sensitivity to the chances of winning (risk adjustment) was related to neural sensitivity to the chances of winning across participants. Whole-brain analysis showed that risk adjustment was positively correlated with neural sensitivity to the chances of winning in active-choice and no-choice trials in the left supramarginal gyrus (peak at $-54,-28,30, t=4.05$ ), the left cuneus (peak at $22,-60,26, t=4.08$ ), and the right precuneus (peak at $8-56,36$, $t=4.41)$. Thus, participants who adjusted their bets more to the chances of winning showed stronger responses to higher likelihood of winning in these brain areas. The reverse contrast did not reveal any significant activations, i.e., areas where neural responsivity to the chances of winning were negatively correlated with risk adjustment. No significant relationships between risk adjustment and neural responsivity in the chances of winning $\times$ choice contrast were found. We additionally tested whether risk adjustment was correlated with neural responsivity in the overall active-choice versus no-choice contrast. No significant activations were found in this analysis.

\section{NEURAL CORRELATES OF MAGNITUDE OF BETS}

Our design also allowed us to identify areas that were sensitive to the magnitude of the bet placed. Specifically, due to the order of the parametric modulators in our design matrix, we could test for areas where the BOLD signal was modulated by the bet size, and was not already explained by the probability modulator. As in the probability analysis, we first identified brain areas that were more responsive to the magnitude of bets during selection in active-choice compared to no-choice trials. In the ROI analysis, no regions were identified that showed such a bet size $\times$ choice interaction. An exploratory whole-brain analysis, however, found this pattern in the supramarginal gyrus bilaterally and the right visual cortex (see Table A3 in Appendix; Figure 4).

We also tested for neural activations that were modulated by the size of bets independently of the choice condition. ROI analysis did not reveal any areas that were significantly modulated by the bet size. However, in the whole-brain analysis, we observed that vmPFC (BA10) and two clusters in left and right caudate were positively correlated with bet size across both choice conditions (see Figure 4 and Table A3 in Appendix). The peak of the vmPFC cluster was just on the border of our ROI, with about half of the cluster located superior to the ROI. The caudate clusters were located in close proximity to, but fully outside, the striatal ROI. No areas in 

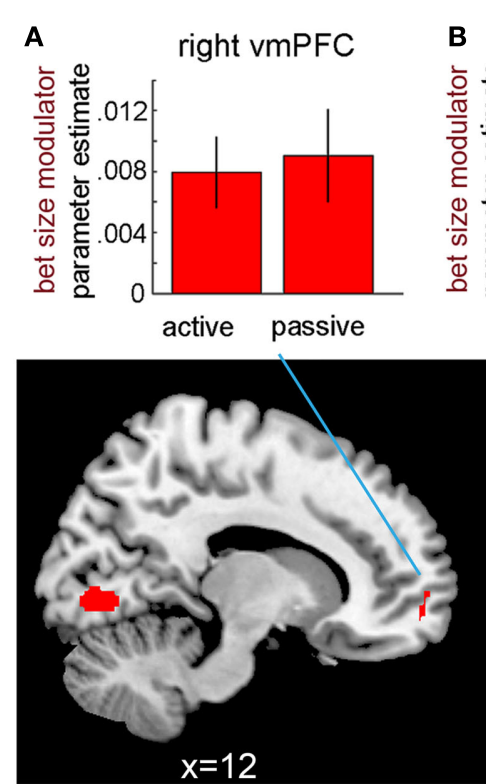
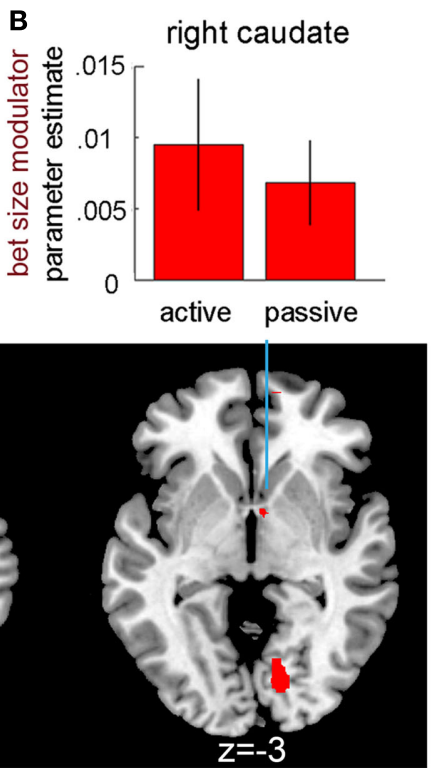
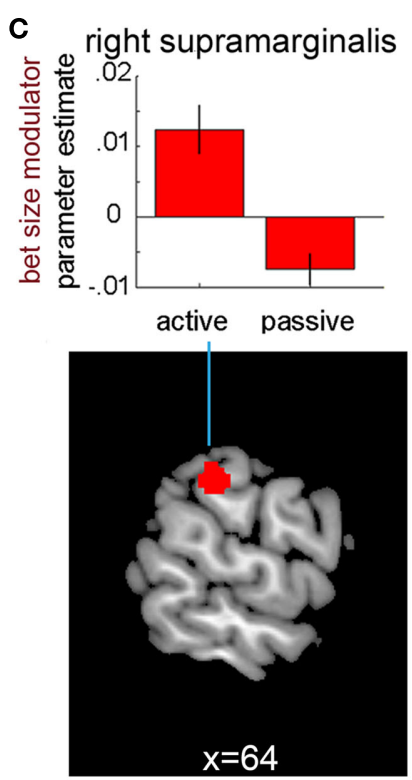

FIGURE 4 | Neural correlates of bet size during selection. Neural responses in the right ventromedial prefrontal cortex (peak at 12, 60, -6) and caudate (peak at $6,2,-2$ ) were correlated with the size of bets during both active and passive bet selection. Furthermore, a bet size $\times$ choice condition interaction was observed in the right supramarginal gyrus (peak at $70,-28,34$ ). Results are displayed at $P<0.001$, uncorrected. Bar graphs show parameter estimates for the bet size modulator in the two choice conditions at peak voxels (A): ventromedial prefrontal cortex, (B): caudate, (C): supramarginal gyrus]. Error bars represent SEM. which responses were negatively correlated with the size of bets were found.

\section{DISCUSSION}

The present study investigated the neural basis of betting choices in healthy subjects using fMRI. We analyzed BOLD responses during the selection phase of the Roulette Betting Task and manipulated choice requirements and the odds of winning. Our first aim was to compare brain responses during volitional (i.e., active, instrumental) versus computer-dictated (passive) bet selection. Active choice of bets was accompanied by increased activity in the striatum, midbrain, medial orbitofrontal cortex, anterior insula, anterior cingulate cortex, visual, and (pre-)motor areas, compared to computer-dictated selection of bets. Our second aim was to assess how the likelihood of winning is neurally represented during active and passive bet selection. ROI analysis showed that the anterior insula bilaterally, IPC bilaterally, right caudate, and vmPFC were particularly sensitive to the chances of winning in active-choice trial, that is to say when this information was used to guide selection. Whole-brain analysis found that the left IPC and right insula correlated with the probability of winning across both active and passive conditions. Individual differences in risk adjustment were positively correlated with neural sensitivity to the chances of winning in the left IPC, across participants.

\section{NEURAL SUBSTRATES OF ACTIVE CHOICE}

Our results highlight the impact of volitional choice upon brain activity during laboratory gambling. Key structures of the brain reward system - specifically the striatum, midbrain, and vmPFC - were more strongly activated during active choice of bets compared to computer-dictated bet selection. We previously showed that psychophysiological arousal is enhanced during active compared to passive bet selection on the same task (Studer and Clark, 2011). In naturalistic gambling, players are more likely to bet and to accept higher risks under conditions of active choice (e.g., selecting lottery numbers) compared to no-choice conditions ("lucky dip"), even in games of pure chance where these manipulations do not affect the likelihood of winning (Henslin, 1967; Langer, 1975; Ladouceur and Mayrand, 1987; Davis et al., 2000). In the brain, instrumental action has previously been found to modulate feedback-related neural activity in the midbrain and striatum (e.g., O’Doherty et al., 2004; Tricomi et al., 2004; Zink et al., 2004; Walton et al., 2007) and active choice of risky gambles has been observed to enhance striatal responses to the presentation of outcomes (Coricelli et al., 2005; Rao et al., 2008; Camille et al., 2011). Our results extend this work by showing that neural activity in the midbrain and striatum is also boosted by active choice at the point of selection, that is to say, during the actual decision period.

The anterior cingulate cortex (ACC) was also more activated during active compared with computer-dictated bet selection. A considerable body of research in non-human primates has revealed that the ACC plays a critical role in active, volitional action selection and instrumental responding (see Walton et al., 2007; Rushworth, 2008; Rushworth and Behrens, 2008 for reviews). Furthermore, previous neuroimaging studies in humans reported that the ACC is activated during volitional action selection in learning environments (e.g., Walton et al., 2004; Behrens et al., 2007). For instance, Walton et al. (2004) assessed neural responses during performance of a higher-order switching task, in which participants received a switch cue and were either instructed which new response rule to follow, or could choose freely. The authors found stronger activations in the ACC during active, self-generated 
rule selection compared to instructed selection. Our results extend these previous findings by showing that the human ACC is also implicated in the volitional choice of (explicitly presented) risky gambles.

\section{NEURAL REPRESENTATION OF THE PROBABILITY OF WINNING DURING BET SELECTION}

The second aim was to identify brain areas that are sensitive to the chances of winning during bet selection, and to test for qualitative and quantitative differences in odds sensitivity under active and passive choice conditions. Neural responses in the IPC (angular and supramarginal gyrus) reflected the chances of winning during the selection phase, and more so in the active-choice condition. Neuroimaging studies on decision-making under risk frequently report activations in the IPC (see Krain et al., 2006; Platt and Huettel, 2008 for reviews), but many studies have failed to consider the functional significance of these activations, often making reverse inferences concerning hypothetical attentional demands. Thus, the role of the IPC in human decision-making has remained poorly specified. A few authors have speculated that the IPC might process the probabilities of outcomes during decision-making under risk (see Ernst et al., 2004; Labudda et al., 2008), in line with the wellestablished role of this region in numerical cognition (for recent reviews, see Ansari, 2008; Sandrini and Rusconi, 2009; Arsalidou and Taylor, 2011). Our results provide correlative evidence for this hypothesis, by showing that neural activity during bet selection in the IPC was modulated by the probability of winning: responses were greater on trials with more favorable odds. Our findings also converge with electrophysiological evidence in non-human primates, which shows that neurons in the posterior parietal cortex represent the probability of rewards during free and forced choice of options with uncertain outcomes (Platt and Glimcher, 1999; McCoy and Platt, 2005; Kable and Glimcher, 2009; Louie and Glimcher, 2010), and reflect choice certainty during perceptual decision-making (Shadlen et al., 1996; Shadlen and Newsome, 2001; Kiani and Shadlen, 2009). Moreover, we found that the IPC was particularly sensitive to the chances of winning in the activechoice condition, i.e., in situations where this information is used to guide risky choice. In close parallel to our results, Mohr et al. (2010) recently argued that the IPC is involved in risk processing during the decision window, but not during outcome anticipation, based on a meta-analysis of prior fMRI studies on decision-making under explicit risk. Finally, we observed that neural sensitivity to the chances of winning within the left supramarginal gyrus was stronger for individuals that adjusted their bets more to the likelihood of winning, i.e., showed a stronger behavioral sensitivity to the chances of winning. Together, these results indicate that the IPC subserves decision-making under explicit risk, and imply that current models of human choice based primarily on fronto-striatal circuitry (e.g., Brand et al., 2006; Frank and Claus, 2006) may be inadequate.

It is noteworthy that the IPC has recently also been implemented in other types of decision-making that do not include uncertain outcomes. Specifically, recent electrophysiological and neuroimaging studies reported that neural responses in the IPC reflect the amount of evidence accumulated for a decision and decision confidence in cost-benefit and perceptual decision-making (e.g., Kiani and Shadlen, 2009; Basten et al., 2010; Kayser et al., 2010). Our results are broadly consistent with these data, as one might speculate that decision confidence increased with the chances of winning on our task.

The IPC has also been implicated in the planning and execution of eye movements (for reviews, see, e.g., Andersen et al., 1992; Pierrot-Deseilligny et al., 1995, 2004; Grosbras et al., 2005). Could it be that the identified parietal activations reflect eye movements in order to gather information about the chances of winning rather than the processing of this information per se? While we have not explicitly controlled for potential eye movements in the data analysis, we think this is unlikely. If the inferior parietal activation reflected eye movements, one would expect stronger responses in trials with lower chances of winning, in which the wheels contained a more balanced number of winning and losing segments. However, we observed the opposite pattern: activations in the IPC were positively correlated with the chances of winning. In other words, responses in the IPC were strongest in the $80 \%$-trials, which contained only two losing segments. There is ample evidence that in the range of 1-4 visual objects, numerosity is assessed in an automatic and fast visual process known as "subitizing" (see Feigenson et al., 2004 for a review). Thus, we posit that the chances of winning in the $80 \%$-trials can easily be assessed at the first glance.

Neural responses during bet selection in the anterior insula were also characterized by an interaction between the probability of winning and the choice condition. Similar to the present results, Clark et al. (2008) found abnormal betting behavior in patients with damage to the insular cortex on the CGT: individuals with insula lesions failed to adjust their bets to the chances of winning. Our finding that neural responses in the anterior insula reflect the chances of winning $\times$ choice condition interaction is also consistent with a study by Rao et al. (2008), who observed differential activations in the anterior insula during voluntary versus involuntary risk-taking on the Balloon Analog Risk Task. The direction of the relationship between neural responses in the anterior insula and the probability of winning differed between active-choice and no-choice trials. During passive bet selection, neural responses in the anterior insula were negatively correlated with the chances of winning, while there was a positive correlation between the probability of winning and insula activity during active choice of bets (see Figure 3). Prior neuroimaging studies by Preuschoff et al. $(2006,2008)$ showed that the anterior insula is sensitive to reward variance during the anticipation of outcomes. In our task, participants tended to select higher bets, and thus took higher risks, when there was a greater probability of winning. Thus, it could be speculated that the anterior insula is sensitive to (subjective) risk during bet selection (see also Bossaerts, 2010). We further observed different activation patterns in the left and right anterior insula. The left anterior insula was primarily modulated by the chances of winning during passive bet selection, while the right anterior insula activation reflected the chances of winning during both volitional and computer-dictated bet selection. In line with these findings, the meta-analysis by Mohr et al. (2010) suggested the right anterior insula to be involved in risk processing during the choice window, whereas the left anterior insula processes outcome uncertainty during anticipation. 
Finally, a probability of winning $\times$ choice condition interaction was also found in the vmPFC and the right caudate. These two regions were additionally sensitive to the size of bets, independent of the choice condition, although it should be noted that the cluster peaks fell outside of our a priori ROI. Prior neuroimaging work has implicated the vmPFC in the subjective valuation of choice options (e.g., Chib et al., 2009; Peters and Büchel, 2009, 2010; Hare et al., 2010; Sescousse et al., 2010). Neuropsychological studies showed that injury to the vmPFC is associated with enhanced risk-taking in everyday life (Eslinger and Damasio, 1985; Shallice and Burgess, 1991; Satish et al., 1999) and poor performance on laboratory gambling tasks (e.g., Bechara et al., 1999; Bechara et al., 2000; Fellows and Farah, 2005, 2007; Weller et al., 2007). Specifically, we previously found that patients with vmPFC-lesions selected higher bets than healthy participants and brain damaged controls on the CGT (Clark et al., 2003, 2008). Another study found impaired probability judgment on the CGT in patients with vmPFC-damage (Rogers et al., 1999). Similarly, neural responses in the ventral striatum have previously been found to reflect the expected value (i.e., the combination of reward magnitude and occurrence probability) of anticipated uncertain outcomes (e.g., Knutson et al., 2005; Preuschoff et al., 2006; Yacubian et al., 2006; Tobler et al., 2007). Here we found that the vmPFC and ventral striatum reflected both the probability and the magnitude of potential wins during risky selection, suggesting that these areas might hold a coordinated representation of these two decision parameters. Indeed, an additional analysis of our data (see Table A5 in Appendix) showed that vmPFC and ventral striatum were sensitive to the expected value of active and passive gambling choices.

\section{REFERENCES}

Andersen, R. A., Brotchie, P. R., and Mazzoni, P. (1992). Evidence for the lateral intraparietal area as the parietal eye field. Curr. Opin. Neurobiol. 2, 840-846.

Ansari, D. (2008). Effects of development and enculturation on number representation in the brain. Nat. Rev. Neurosci. 9, 278-291.

Arsalidou, M., and Taylor, M. J. (2011). Is $2+2=4$ ? meta-analyses of brain areas needed for numbers and calculations. Neuroimage 54, 2382-2393.

Basten, U., Biele, G., Heekeren, H. R., and Fiebach, C. J. (2010). How the brain integrates costs and benefits during decision making. Proc. Natl. Acad. Sci. U.S.A. 107, 1767-1772.

Bechara, A., Damasio, H., and Damasio, A. R. (2000). Emotion, decision making and the orbitofrontal cortex. Cereb. Cortex 10, 295-307.

Bechara, A., Damasio, H., Damasio, A. R., and Lee, G. P. (1999). Different contributions of the human amygdala and ventromedial prefrontal cortex to decision-making. J. Neurosci. 19, 5473-5481.
Behrens, T. E. J., Woolrich, M. W., Walton, M. E., and Rushworth, M. F. S. (2007). Learning the value of information in an uncertain world. Nat. Neurosci. 10, 1214-1221.

Bossaerts, P. (2010). Risk and risk prediction error signals in anterior insula. Brain Struct. Funct. 214, 645-653.

Brand, M., Labudda, K., and Markowitsch, H. J. (2006). Neuropsychological correlates of decision-making in ambiguous and risky situations. Neural Netw. 19, 1266-1276.

Camille, N., Pironti, V., Dodds, C., Aitken, M., Robbins, T., and Clark, L. (2011). Striatal sensitivity to personal responsibility in a regret-based decision-making task. Cogn. Affect. Behav. Neurosci. 10, 460-469.

Chib, V. S., Rangel, A., Shimojo, S., and O'Doherty, J. P. (2009). Evidence for a common representation of decision values for dissimilar goods in human ventromedial prefrontal cortex. J. Neurosci. 29, 12315-12320.

Clark, L., Bechara, A., Damasio, H., Aitken, M. R. F., Sahakian, B. J.,

\section{CONCLUSION}

Our results highlight the impact of active choice upon the neural correlates of gambling: a distributed network of brain regions was more activated during volitional compared to computer-dictated bet selection, including key areas of the brain reward system, namely the midbrain, striatum, and vmPFC. In line with previous neuropsychological data, we found that the vmPFC and anterior insula are involved in betting choices. Our data also provide correlative evidence for a role of the IPC in human decision-making under risk linked to the processing of outcome probabilities. Neural responses during the selection phase in the IPC reflected the probability of winning, especially so in the active-choice condition. In other words, the IPC was particularly implicated in situations where the processing of probability information was required to guide bet selection. Our data converge with recent findings of electrophysiological research in non-human primates and suggest that current models of human decision-making under risk focused on fronto-striatal circuitry should be extended to include interactions with the IPC.

\section{ACKNOWLEDGMENTS}

This research was supported by a James McDonnell Foundation network grant (grant number: 22002015501 - RG51821). The study was completed within the Behavioral and Clinical Neuroscience Institute, supported by a consortium award from the MRC and Wellcome Trust. We would like to thank the radiographers and staff at the Wolfson Brain Imaging Centre, Cambridge UK for their assistance in the acquisition of MRI data, and Dr. Jon Roiser and Dr. Anna Barnes for valuable advice on MRI data analysis.

and Robbins, T. W. (2008). Differential effects of insular and ventromedial prefrontal cortex lesions on risky decision-making. Brain 131, 1311-1322.

Clark, L., Manes, F., Antoun, N. Sahakian, B. J., and Robbins, T. W. (2003). The contributions of lesion laterality and lesion volume to decision-making impairment following frontal lobe damage. $\mathrm{Neu}$ ropsychologia 41, 1474-1483.

Coricelli, G., Critchley, H. D., Joffily, M., O’Doherty, J. P., Sirigu, A., and Dolan, R. J. (2005). Regret and its avoidance: a neuroimaging study of choice behavior. Nat. Neurosci. 8, 1255-1262.

Critchley, H. D., Mathias, C. J., and Dolan, R. J. (2001). Neural activity in the human brain relating to uncertainty and arousal during anticipation. Neuron 29, 537-545.

Davis, D., Sundahl, I., and Lesbo, M. (2000). Illusory personal control as a determinant of bet size and type in casino craps games. J. Appl. Soc. Psychol. 30, 1224-1242.

Elliott, R., Agnew, Z., and Deakin, J. F. W. (2008). Medial orbitofrontal cortex codes relative rather than absolute value of financial rewards in humans. Eur. J. Neurosci. 27, 2213-2218.

Ernst, M., Nelson, E. E., McClure, E. B., Monk, C. S., Munson, S., Eshel, N., Zarahn, E., Leibenluft, E., Zametkin, A., Towbin, K., Blair, J., Charney, D., and Pine, D. S. (2004). Choice selection and reward anticipation: an fMRI study. Neuropsychologia 42, 1585-1597.

Ernst, M., and Paulus, M. P. (2005). Neurobiology of decision making: a selective review from a neurocognitive and clinical perspective. Biol. Psychiatry 58, 597-604.

Eslinger, P. J., and Damasio, A. R. (1985). Severe disturbance of higher cognition after bilateral frontal lobe ablation: patient EVR. Neurology 35, 1731.

Feigenson, L., Dehaene, S., and Spelke, E. (2004). Core systems of number. Trends Cogn. Sci. (Regul. Ed.) 8, 307-314.

Fellows, L. K., and Farah, M. J. (2005). Different underlying impairments in decision-making following ventromedial and dorsolateral frontal lobe damage in humans. Cereb. Cortex 15, 58-63. 
Fellows, L. K., and Farah, M. J. (2007). The role of ventromedial prefrontal cortex in decision making: judgment under uncertainty or judgment per se? Cereb. Cortex 17, 2669-2674.

Frank, M. J., and Claus, E. D. (2006). Anatomy of a decision: striatoorbitofrontal interactions in reinforcement learning, decision making, and reversal. Psychol. Rev. 113, 300-326.

Gläscher, J. (2009). Visualization of group inference data in functional neuroimaging. Neuroinformatics 7, 73-82.

Grosbras, M.-H., Laird, A. R., and Paus, T. (2005). Cortical regions involved in eye movements, shifts of attention, and gaze perception. Hum. Brain Mapp. 25, 140-154.

Hare, T. A., Camerer, C. F., Knoepfle, D. T., O'Doherty, J. P., and Rangel, A. (2010). Value computations in ventral medial prefrontal cortex during charitable decision making incorporate input from regions involved in social cognition. J. Neurosci. 30, 583-590.

Hare, T. A., O’Doherty, J., Camerer, C. F., Schultz, W., and Rangel, A. (2008). Dissociating the role of the orbitofrontal cortex and the striatum in the computation of goal values and prediction errors. J. Neurosci. 28, 5623-5630.

Henslin, J. M. (1967). Craps and magic. Am. J. Sociol. 73, 316.

Huettel, S. A., Song, A. W., and McCarthy, G. (2005). Decisions under uncertainty: probabilistic context influences activation of prefrontal and parietal cortices. $J$. Neurosci. 25, 3304-3311.

Hutton, S. B., Murphy, F. C., Joyce, E. M., Rogers, R. D., Cuthbert, I., Barnes, T. R. E., McKenna, P. J., Sahakian, B. J., and Robbins, T. W. (2002). Decision making deficits in patients with first-episode and chronic schizophrenia. Schizophr. Res. 55, 249-257.

Kable, J. W., and Glimcher, P. W. (2009). The neurobiology of decision: consensus and controversy. Neuron 63, 733-745.

Kayser, A. S., Buchsbaum, B. R., Erickson, D. T., and D'Esposito, M. (2010). The functional anatomy of a perceptual decision in the human brain. J. Neurophysiol. 103, 1179-1194.

Kiani, R., and Shadlen, M. N. (2009). Representation of confidence associated with a decision by neurons in the parietal cortex. Science 324, 759-764.
Knutson, B., Adams, C. M., Fong, G. W., and Hommer, D. (2001). Anticipation of increasing monetary reward selectively recruits nucleus accumbens. J. Neurosci. 21, RC159.

Knutson, B., and Greer, S. M. (2008). Anticipatory affect: neural correlates and consequences for choice. Philos. Trans. R. Soc. B Biol. Sci. 363, 3771-3786.

Knutson, B., Taylor, J., Kaufman, M., Peterson, R., and Glover, G. (2005). Distributed neural representation of expected value. J. Neurosci. 25, 4806-4812.

Krain, A. L., Wilson, A. M., Arbuckle, R., Castellanos, F. X., and Milham, M. P. (2006). Distinct neural mechanisms of risk and ambiguity: a metaanalysis of decision-making. Neuroimage 32, 477-484.

Labudda, K., Woermann, F., Mertens, M., Pohlmann-Eden, B., Markowitsch, H., and Brand, M. (2008). Neural correlates of decision making with explicit information about probabilities and incentives in elderly healthy subjects. Exp. Brain Res. 187, 641-650.

Ladouceur, R., and Mayrand, M. (1987). The level of involvement and the timing of betting in roulette. J. Psychol. $121,169$.

Langer, E. J. (1975). The illusion of control. J. Pers. Soc. Psychol. 32, 311-328.

Lawrence, A. J., Luty, J., Bogdan, N. A., Sahakian, B. J., and Clark, L. (2009). Problem gamblers share deficits in impulsive decision-making with alcohol-dependent individuals. Addiction 104, 1006-1015.

Liu, X., Hairston, J., Schrier, M., and Fan, J. (2011). Common and distinct networks underlying reward valence and processing stages: a meta-analysis of functional neuroimaging studies. Neurosci. Biobehav. Rev. 35, 1219-1236.

Louie, K., and Glimcher, P. W. (2010). Separating value from choice: delay discounting activity in the lateral intraparietal area. J. Neurosci. 30, 5498-5507.

Maldjian, J. A., Laurienti, P. J., and Burdette, J. H. (2004). Precentral gyrus discrepancy in electronic versions of the Talairach atlas. Neuroimage 21, 450-455.

Maldjian, J. A., Laurienti, P. J., Kraft, R. A., and Burdette, J. H. (2003). An automated method for neuroanatomic and cytoarchitectonic atlas-based interrogation of fMRI data sets. Neuroimage 19, 1233-1239.

Manes, F., Sahakian, B., Clark, L., Rogers, R., Antoun, N., Aitken, M., and Robbins, T. (2002). Decisionmaking processes following damage to the prefrontal cortex. Brain 125 624-639.

Mavaddat, N., Kirkpatrick, P. J., Rogers, R. D., and Sahakian, B. J. (2000). Deficits in decision-making in patients with aneurysms of the anterior communicating artery. Brain 123, 2109-2117.

McCoy, A. N., and Platt, M. L. (2005). Expectations and outcomes: decision-making in the primate brain. J. Comp. Physiol. A Neuroethol. Sens. Neural Behav. Physiol. 191, 201-211.

Mohr, P. N. C., Biele, G., and Heekeren, H. R. (2010). Neural processing of risk. J. Neurosci. 30, 6613-6619.

Murphy, F. C., Rubinsztein, J. S., Michael, A., Rogers, R. D., Robbins, T. W., Paykel, E. S., and Sahakian, B. J. (2001). Decision-making cognition in mania and depression. Psychol. Med. 31, 679-693.

O’Doherty, J., Dayan, P., Schultz, J., Deichmann, R., Friston, K., and Dolan, R. J. (2004). Dissociable roles of ventral and dorsal striatum in instrumental conditioning. Science 304, 452-454.

Peters, J., and Büchel, C. (2009). Overlapping and distinct neural systems code for subjective value during intertemporal and risky decision making. J. Neurosci. 29, 15727-15734.

Peters, J., and Büchel, C. (2010). Neural representations of subjective reward value. Behav. Brain Res. 213, 135-141.

Pierrot-Deseilligny, C., Rivaud, S., Gaymard, B., Müri, R., and Vermersch, A.-I. (1995). Cortical control of saccades. Ann. Neurol. 37, 557-567.

Pierrot-Deseilligny, C. A., Milea, D. B., and Muri, R. M. C. (2004). Eye movement control by the cerebral cortex. Curr. Opin. Neurol. 17, 17-25.

Plassmann, H., O’Doherty, J. P., and Rangel, A. (2010). Appetitive and aversive goal values are encoded in the medial orbitofrontal cortex at the time of decision making. J. Neurosci. 30, 10799-10808.

Platt, M. L., and Glimcher, P. W. (1999). Neural correlates of decision variables in parietal cortex. Nature 400, 233-238.

Platt, M. L., and Huettel, S. A. (2008). Risky business: the neuroeconomics of decision making under uncertainty. Nat. Neurosci. 11, 398-403.

Preuschoff, K., Bossaerts, P., and Quartz, S. R. (2006). Neural differentiation of expected reward and risk in human subcortical structures. Neuron 51, 381-390.

Preuschoff, K., Quartz, S. R., and Bossaerts, P. (2008). Human insula activation reflects risk prediction errors as well as risk. J. Neurosci. 28, 2745-2752.

Rao, H., Korczykowski, M., Pluta, J., Hoang, A., and Detre, J. A. (2008). Neural correlates of voluntary and involuntary risk taking in the human brain: an fMRI study of the balloon analog risk task (BART). Neuroimage 42, 902-910.

Rogers, R. D., Everitt, B. J., Baldacchino, A., Blackshaw, A. J., Swainson, R., Wynne, K., Baker, N. B., Hunter, J., Carthy, T., Booker, E., London, M., Deakin, J. F. W., Sahakian, B. J., and Robbins, T. W. (1999). Dissociable deficits in the decision-making cognition of chronic amphetamine abusers, opiate abusers, patients with focal damage to prefrontal cortex, and tryptophan-depleted normal volunteers: evidence for monoaminergic mechanisms. Neuropsychopharmacology 20, 322-339.

Roiser, J. P., Cannon, D. M., Gandhi, S. K., Tavares, J. T., Erickson, K., Wood, S., Klaver, J. M., Clark, L., Zarate, C. A. Jr., Sahakian, B. J., and Drevets, W. C. (2009). Hot and cold cognition in unmedicated depressed subjects with bipolar disorder. Bipolar Disord. 11, 178-189.

Rolls, E. T., and Grabenhorst, F. (2008). The orbitofrontal cortex and beyond: from affect to decision-making. Prog. Neurobiol. 86, 216-244.

Rushworth, M. F. S. (2008). Intention, choice, and the medial frontal cortex. Ann. N. Y. Acad. Sci. 1124, 181-207.

Rushworth, M. F. S., and Behrens, T. E. J. (2008). Choice, uncertainty and value in prefrontal and cingulate cortex. Nat. Neurosci. 11, 389-397.

Sandrini, M., and Rusconi, E. (2009). A brain for numbers. Cortex 45, 796-803.

Satish, U., Streufert, S., and Eslinger, P. J. (1999). Complex decision making after orbitofrontal damage: neuropsychological and strategic management simulation assessment. Neurocase 5, 355-364.

Sescousse, G., Redoute, J., and Dreher, J.-C. (2010). The architecture of reward value coding in the human orbitofrontal cortex. J. Neurosci. 30 13095-13104.

Shadlen, M., Britten, K., Newsome, W., and Movshon, J. (1996). A computational analysis of the relationship between neuronal 
and behavioral responses to visual motion. J. Neurosci. 16, 1486-1510.

Shadlen, M. N., and Newsome, W. T. (2001). Neural basis of a perceptual decision in the parietal cortex (area LIP) of the rhesus monkey. J. Neurophysiol. 86, 1916-1936.

Shallice, T. I. M., and Burgess, P. W. (1991). Deficits in strategy application following frontal lobe damage in man. Brain 114, 727-741.

Sharot, T., De Martino, B., and Dolan, R. J. (2009). How choice reveals and shapes expected hedonic outcome. J. Neurosci. 29, 3760-3765.

Smith, B. W., Mitchell, D. G. V., Hardin, M. G., Jazbec, S., Fridberg, D., Blair, R. J. R., and Ernst, M. (2009). Neural substrates of reward magnitude, probability, and risk during a wheel of fortune decisionmaking task. Neuroimage 44, 600-609.

Studer, B., and Clark, L. (2011). Place your bets: psychophysiological correlates of decision-making under risk. Cogn. Affect. Behav. Neurosci. 11, 144-158.

Symmonds, M., Bossaerts, P., and Dolan, R. J. (2010). A behavioral and neural evaluation of prospective decision-making under risk. $J$. Neurosci. 30, 14380-14389.
Talairach, J., and Tournoux, P. (1988). Co-planar Stereotaxic Atlas of the Human Brain: 3-Dimensional Proportional System - an Approach to Cerebral Imaging. New York: Thieme Medical Publishers.

Tobler, P. N., Christopoulos, G. I., O'Doherty, J. P., Dolan, R. J., and Schultz, W. (2009). Risk-dependent reward value signal in human prefrontal cortex. Proc. Natl. Acad. Sci. U.S.A. 106, 7185-7190.

Tobler, P. N., O’Doherty, J. P., Dolan, R. J., and Schultz, W. (2007). Reward value coding distinct from risk attitude-related uncertainty coding in human reward systems. J. Neurosci. 97, 1621-1632.

Tom, S. M., Fox, C. R., Trepel, C., and Poldrack, R. A. (2007). The neural basis of loss aversion in decisionmaking under risk. Science 315, 515-518.

Tricomi, E. M., Delgado, M. R., and Fiez, J. A. (2004). Modulation of caudate activity by action contingency. Neuron 41, 281-292.

Tzourio-Mazoyer, N., Landeau, B., Papathanassiou, D., Crivello, F., Etard, O., Delcroix, N., Mazoyer, B., and Joliot, M. (2002). Automated anatomical labeling of activations in SPM using a macroscopic anatomical parcellation of the MNI MRI single-subject brain. Neuroimage 15 , 273-289.

Van Leijenhorst, L., Crone, E. A., and Bunge, S. A. (2006). Neural correlates of developmental differences in risk estimation and feedback processing. Neuropsychologia 44, 2158-2170.

Walton, M. E., Croxson, P. L., Behrens, T. E. J., Kennerley, S. W., and Rushworth, M. F. S. (2007). Adaptive decision making and value in the anterior cingulate cortex. Neuroimage 36, T142-T154.

Walton, M. E., Devlin, J. T., and Rushworth, M. F. S. (2004). Interactions between decision making and performance monitoring within prefrontal cortex. Nat. Neurosci. 7, 1259-1265.

Weller, J. A., Levin, I. P., Shiv, B., and Bechara, A. (2007). Neural correlates of adaptive decision making for risky gains and losses. Psychol. Sci. 18, 958-964.

Yacubian, J., Gläscher, J., Schroeder, K., Sommer, T., Braus, D. F., and Büchel, C. (2006). Dissociable systems for gain- and loss-related value predictions and errors of prediction in the human brain. J. Neurosci. 26, 9530-9537.

Zink, C. F., Pagnoni, G., MartinSkurski, M. E., Chappelow, J. C., and
Berns, G. S. (2004). Human striatal responses to monetary reward depend on saliency. Neuron 42, 509-517.

Conflict of Interest Statement: The authors declare that the research was conducted in the absence of any commercial or financial relationships that could be construed as a potential conflict of interest.

Received: 13 January 2012; accepted: 20 March 2012; published online: 18 April 2012.

Citation: Studer B, Apergis-Schoute AM, Robbins TW and Clark L (2012) What are the odds? The neural correlates of active choice during gambling. Front. Neurosci. 6:46. doi: 10.3389/fnins.2012.00046

This article was submitted to Frontiers in Decision Neuroscience, a specialty of Frontiers in Neuroscience.

Copyright (C) 2012 Studer, ApergisSchoute, Robbins and Clark. This is an open-access article distributed under the terms of the Creative Commons Attribution Non Commercial License, which permits non-commercial use, distribution, and reproduction in other forums, provided the original authors and source are credited. 


\section{APPENDIX}

Table A1 | Neural correlates of active compared to passive selection of bets identified in the exploratory whole-brain analysis $(P<0.001, k=10)$.

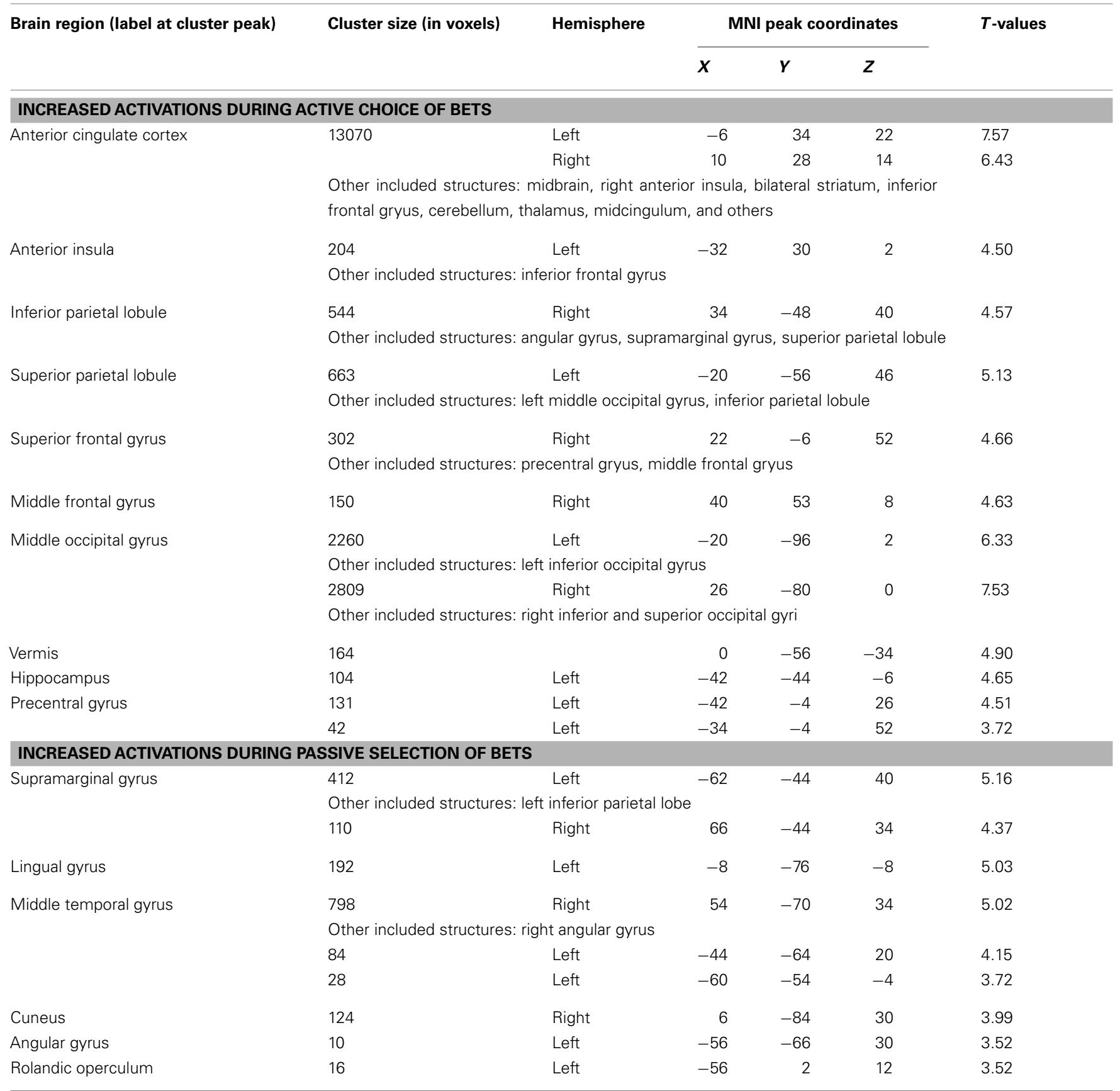


Table A2 | Neural correlates of probability of winning during bet selection (whole-brain analysis, $P<0.001, k=10$ ).

\begin{tabular}{lllll} 
Brain region (label at cluster peak) & Cluster size (in voxels) & Hemisphere & \multicolumn{2}{c}{ MNI peak coordinates } \\
\cline { 3 - 4 } & & $X$-values
\end{tabular}

\begin{tabular}{|c|c|c|c|c|c|c|}
\hline \multicolumn{7}{|c|}{ ACTIVATIONS DISPLAYING A PROBABILITY OF WINNING $\times$ CHOICE INTERACTION } \\
\hline Ventromedial prefrontal cortex* & 1473 & Bilateral & -4 & 28 & -8 & 6.72 \\
\hline \multirow[t]{3}{*}{ Inferior frontal gyrus (orbital part) } & 815 & Left & -52 & 2 & -28 & 5.69 \\
\hline & \multicolumn{6}{|c|}{ Other included structures: left anterior insula, temporal pole, inferior frontal gyrus (triar } \\
\hline & 50 & Left & -38 & 30 & -8 & 4.25 \\
\hline \multirow[t]{2}{*}{ Angular gyrus* } & 315 & Right & 62 & -56 & 32 & 5.28 \\
\hline & \multicolumn{6}{|c|}{ Other included structures: right middle* and superior temporal gyrus* } \\
\hline \multirow[t]{5}{*}{ Middle temporal gyrus* } & 717 & Left & -56 & -66 & 26 & 5.76 \\
\hline & \multicolumn{6}{|c|}{ Other included structures: left angular gyrus* } \\
\hline & 23 & Left & -66 & -36 & -2 & 4.04 \\
\hline & 25 & Left & -64 & -24 & -12 & 3.96 \\
\hline & 35 & Right & 60 & -4 & 22 & 4.19 \\
\hline \multirow[t]{5}{*}{ Lingual gyrus* } & 466 & Left & -28 & -56 & 0 & 5.12 \\
\hline & \multicolumn{6}{|c|}{ Other included structures: left cerebellum* } \\
\hline & 529 & Right & 20 & -74 & 2 & 4.98 \\
\hline & \multicolumn{6}{|c|}{ Other included structures: right calcarine gyrus } \\
\hline & 105 & Right & 12 & -30 & -6 & 4.35 \\
\hline Anterior insula* & 85 & Right & 38 & 20 & -22 & 4.58 \\
\hline Supramarginal gyrus & 40 & Right & 66 & -22 & 22 & 4.08 \\
\hline \multirow[t]{3}{*}{ Caudate } & 15 & Left & -10 & 4 & 18 & 3.72 \\
\hline & 20 & Left & -8 & 14 & 2 & 3.71 \\
\hline & 88 & Right & 10 & 6 & -2 & 4.28 \\
\hline Midcingulate cortex* & 300 & Left & -8 & -12 & 42 & 4.47 \\
\hline
\end{tabular}

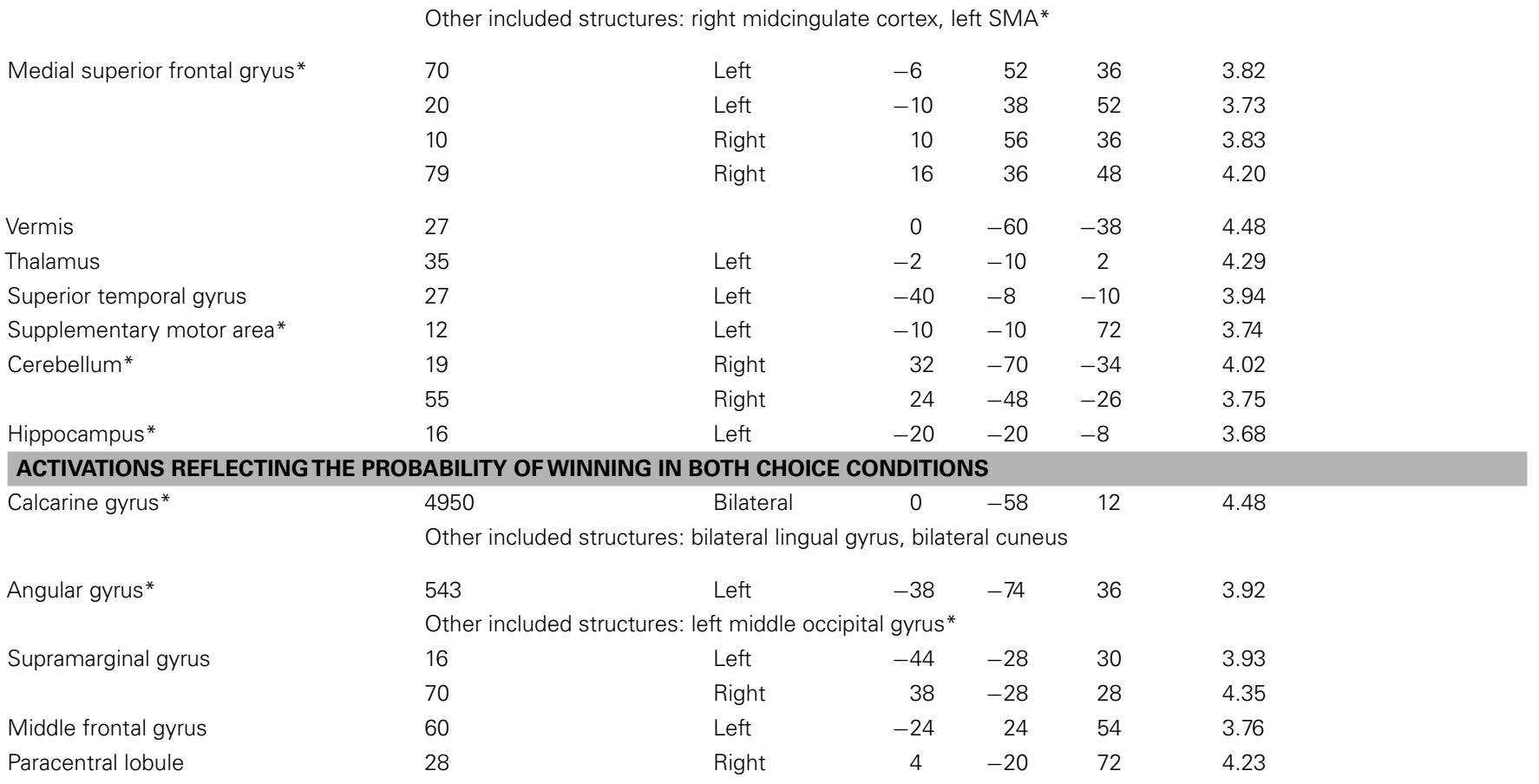


Table A2 | Continued

\begin{tabular}{|c|c|c|c|c|c|c|}
\hline \multirow[t]{2}{*}{ Brain region (label at cluster peak) } & \multirow[t]{2}{*}{ Cluster size (in voxels) } & \multirow[t]{2}{*}{ Hemisphere } & \multicolumn{3}{|c|}{ MNI peak coordinates } & \multirow[t]{2}{*}{$T$-values } \\
\hline & & & $x$ & $Y$ & $z$ & \\
\hline \multirow[t]{2}{*}{ Cerebellum } & 42 & Right & 22 & -50 & -30 & 4.00 \\
\hline & 22 & Right & 20 & -80 & -26 & 3.60 \\
\hline Fusiform gyrus & 27 & Left & -24 & -32 & -18 & 3.39 \\
\hline
\end{tabular}

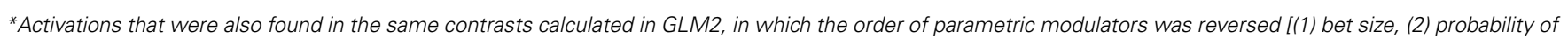
winning]. Thus, these areas represented the probability of winning independently of the bet size.

Table A3 | Neural correlates of bet size during selection (whole-brain analysis, $P<0.001, k=10$ ).

\begin{tabular}{|c|c|c|c|c|c|c|}
\hline \multirow[t]{2}{*}{ Brain region (label at cluster peak) } & \multirow[t]{2}{*}{ Cluster size (in voxels) } & \multirow[t]{2}{*}{ Hemisphere } & \multicolumn{3}{|c|}{ MNI peak coordinates } & \multirow[t]{2}{*}{$T$-values } \\
\hline & & & $x$ & $\boldsymbol{Y}$ & $Z$ & \\
\hline \multicolumn{7}{|c|}{ ACTIVATIONS DISPLAYING A BET SIZE $\times$ CHOICE INTERACTION } \\
\hline \multirow[t]{2}{*}{ Supramarginal gyrus } & 13 & Left & -66 & -30 & 34 & 3.72 \\
\hline & 185 & Right & 70 & -28 & 34 & 4.70 \\
\hline Lingual gyrus & 139 & Right & 12 & -74 & 0 & 4.54 \\
\hline Ventromedial prefrontal cortex & 30 & Right & 12 & 60 & -6 & 4.36 \\
\hline \multirow[t]{2}{*}{ Caudate } & 27 & Right & 6 & 2 & -2 & 4.16 \\
\hline & 30 & Left & -22 & -2 & 18 & 3.98 \\
\hline Lingual gyrus & 230 & Right & 12 & -78 & -2 & 4.37 \\
\hline Precuneus & 48 & Right & 20 & -56 & 36 & 4.36 \\
\hline Middle occipital gyrus & 25 & Left & -26 & -58 & 28 & 4.01 \\
\hline
\end{tabular}


Table A4 | Neural correlates during feedback (whole-brain analysis, FWE-corrected, $P<0.05, k=10$ ).

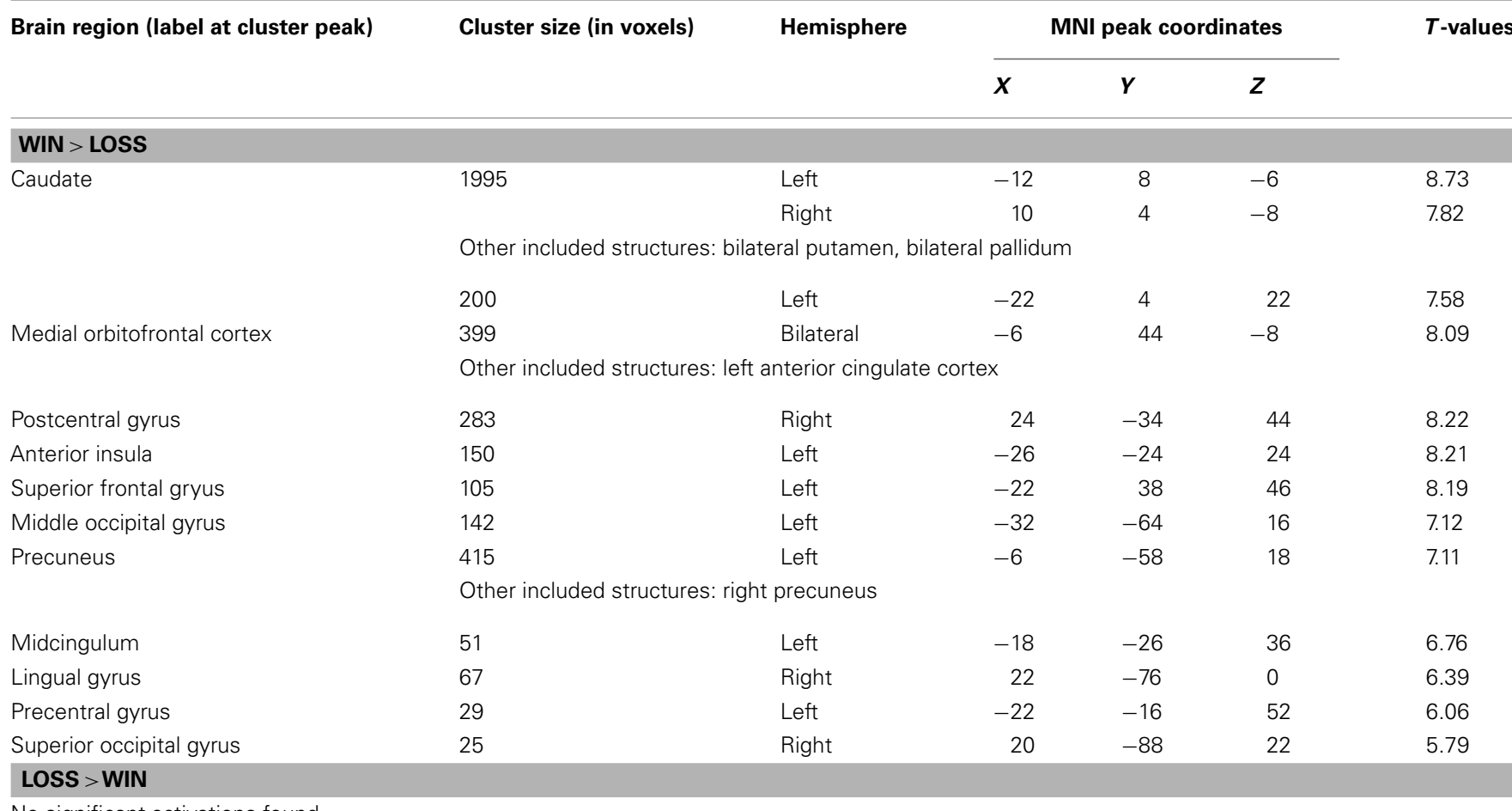

No significant activations found

Table A5 | Neural correlates of expected value during selection (GLM3, ROI analysis, $P<0.001$, FDR-corrected, $k=10$ ).

\begin{tabular}{llll}
\hline Brain region (label at cluster peak) $\quad$ Cluster size (in voxels) & Hemisphere & \multicolumn{2}{c}{ MNI peak coordinates } \\
\cline { 3 - 4 } & $X \quad Y \quad Z \quad$-values
\end{tabular}

\section{ACTIVATIONS DISPLAYING AN EXPECTED VALUE $\times$ CHOICE INTERACTION}

No significant activations found

\section{ACTIVATIONS REFLECTING EXPECTED VALUE IN BOTH CHOICE CONDITIONS}

Medial orbitofrontal gyrus

Angular gyrus

Caudate

Putamen
670

673

Other included structures: left supramarginal gyrus

$2 \quad 56 \quad-12 \quad 4.67$

$\begin{array}{llll}-54 & -64 & 26 & 4.29\end{array}$

Right

Left

8

$-22$

6

$-2$

3.46

11

$-2$

$14 \quad 3.43$


Table A6 | Neural correlates of expected value during selection (GLM3, whole-brain analysis, $P<0.001, k=10$ ).

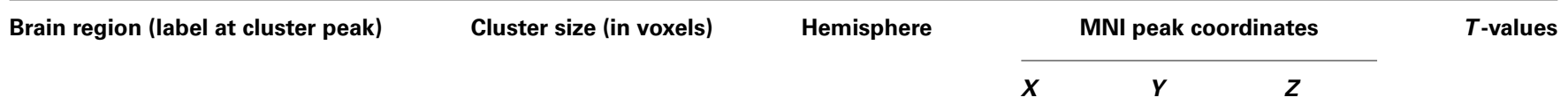

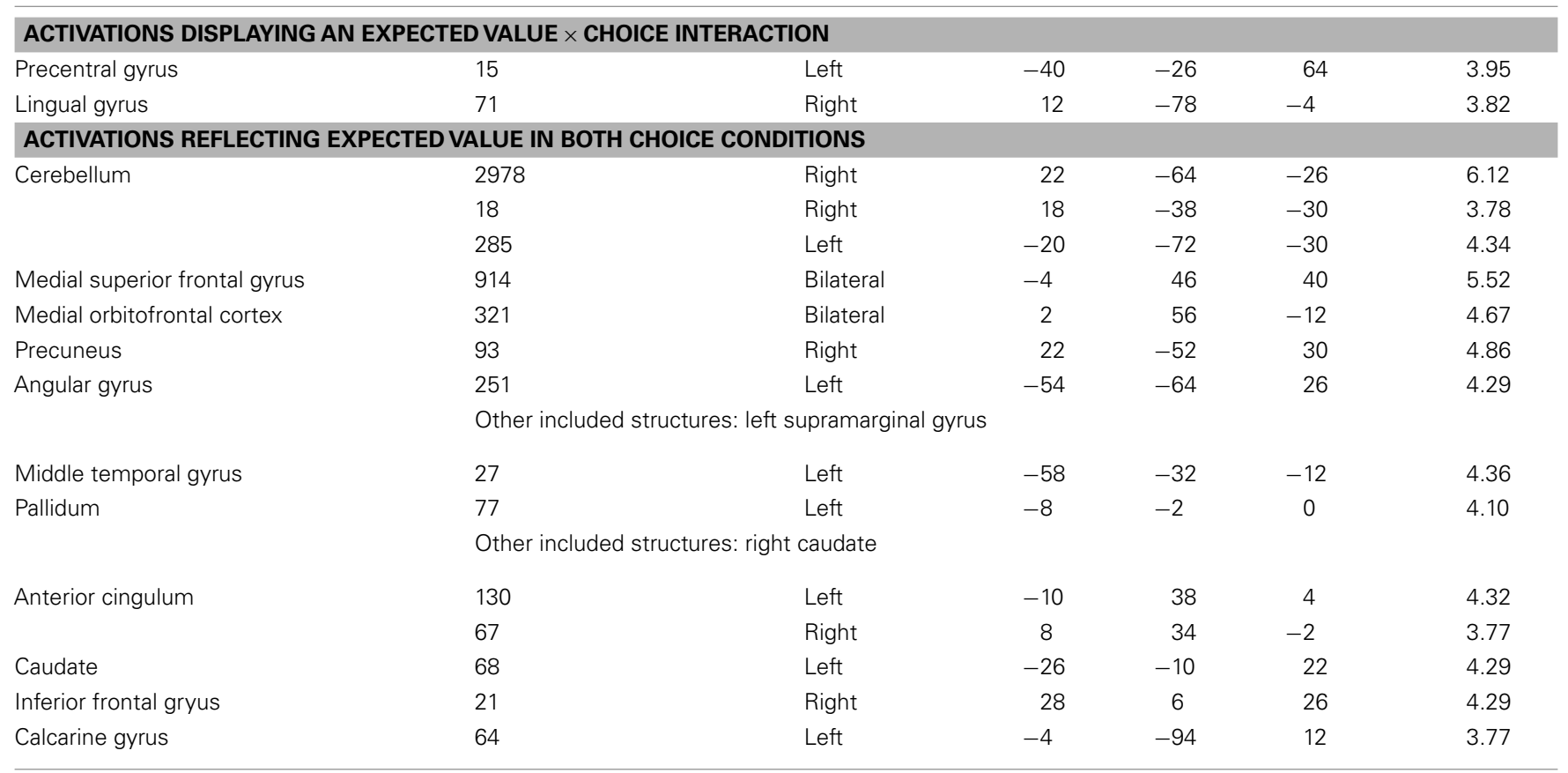

